\title{
How to Choose Mutual Funds that Perform Well? Evidence from Taiwan
}

\author{
Li-Chang Hsu \\ Department of Finance, Ling Tung University \\ 1 Ling Tung Road, Nantun, Taichung 40852, Taiwan, R.O.C. \\ Tel: 886-4-2389-2088 Ext.3642Ｅ-mail: ltctht87@mail.ltu.edu.tw \\ Shang-Ling Ou \\ Department of Agronomy, National Chung Hsing University \\ 250 KuoKuang Rd., Taichung 40227, Taiwan, R.O.C.
}

Tel: 886-4-2284-0777 Ext.203Ｅ-mail: slou@dragon.nchu.edu.tw

Chia-Chen Yang

Department of Finance, Ling Tung University

1 Ling Tung Road, Nantun, Taichung 40852, Taiwan, R.O.C.

Tel: 886-4-2389-2088 Ext.3642Ｅ-mail: ycc@teamail.ltu.edu.tw

Yih-Chang Ou (Corresponding author)

Department of Finance, Ling Tung University

1 Ling Tung Road, Nantun, Taichung 40852, Taiwan, R.O.C.

Tel: 886-4-2389-2088 Ext.3642 E-mail: ycou@mail.ltu.edu.tw

Received: July 28, 2011

doi:10.5539/ijef.v4n1p247
Accepted: August 12, 2011

Published: January 1, 2012

URL: http://dx.doi.org/10.5539/ijef.v4n1p247

\begin{abstract}
This study aimed to examine the performance evaluation and persistence of equity mutual funds when the market reverses from a bull market to a bear market. We also attempt to find the appropriate performance evaluation indicators when funds exhibit performance reversal. Such an indicator will be of great assistance to investors in making investment decisions. Therefore, this study investigates the performance of 30 equity mutual funds in Taiwan. The data cover 500 dealing days from November 2006 to October 2008, with an emphasis on the 2007 financial crisis. There were two main findings in our study. First, we found that different performance measures led to significantly diverging rankings of mutual funds in different market climates. Second, the result of the persistence test showed that when the market climate shifts from bull to bear market, using the GRAROC model is the best indicator of future mutual fund performance.
\end{abstract}

Keywords: Risk adjusted return on capital, Value at risk, Performance evaluation, Persistence, Mutual funds

\section{Introduction}

There are a lot of different mutual funds in the investment world. Therefore, choosing profitable mutual funds for investment is a very important issue. Many scholars have shown that investors buy funds based on the fund's past performance as their selection criteria, under circumstances of limited information. That is, if performance ratings are persistence, then funds investors can choose an appropriate mutual fund to invest in. Therefore, fund performance persistence has become an important research topic. Analysis of mutual fund performance and persistence is not a new area. Accordingly, this study aims to identify fund performance evaluation and persistence indicators for investors facing different market climates (from bull to bear). This would provide investors with an important reference for future investment decisions. In order to examine the above-mentioned issues, we choose the mutual funds in Taiwan as our objective market. 
Taiwan's mutual fund market was first established in 1983, compared to the United Kingdom and the United States had a slow start, but the scale of the funds with highly growth potential. Mutual funds have become one of the most popular investment instruments for Taiwan's investors (Lin and Chen, 2008). According to Securities Investment Trust \& Consulting Association of the R.O.C. (SITCA), there are various kinds of equity mutual funds in a total amount of 221, and with the scale of the NT\$321.26 billion in the end of 2001. By the end of January 2011, there were already 334 equity mutual funds in Taiwan, with managed assets reaching NT\$ 685.96 billion. The asset scale of Taiwan's equity mutual funds had a growth rate of 113.5 percent over the past ten years. The equity mutual fund market in Taiwan still has great potential for growth. However, as an emerging economy, it has long been ignored by investors in developed countries.

Despite the economic significance of the Taiwan equity mutual fund market, it still remains an under-researched area. Taiwan's equity mutual fund market is still playing important player in the global financial markets. Only a few studies have been conducted. For example, Chen and Huang (2009) proposed a portfolio selection model with fuzzy returns, and demonstrated by Taiwan equity mutual funds. Chang et al. (2010) using TOPSIS methods incorporated Minkowski's distance measure to evaluate the Taiwan mutual funds' performance. This is why this study selected the Taiwan's equity mutual funds as our research target.

Since the 1960s, many scholars have believed that investors consider the amount of the returns and risk when conducting investment. A variety of mutual fund performance evaluation techniques have been proposed, such as the Treynor ratio (Treynor, 1965), Sharpe ratio (Sharpe, 1966) and Jensen's alpha (Jensen, 1968). Among them, one of the most commonly used evaluation indicators is the Sharpe ratio (Goltz and Schroeder, 2008). Although this type of indicator is widely used in the research field, there are many problems that need to be addressed. For example, the Sharpe ratio uses the standard deviation of returns as the measure of risk. This may not fully reflect the true risk. If used of the Sharpe ratio in bear market could give misleading results in their investment decisions (Israelsen, 2005; Scholz, 2006). The Treynor ratio uses risk adjustment factor (beta factor) as the systematic risk measure, but when the investment market is in long or short positions, the systematic risk level can be interpreted in different ways. Furthermore, the Jensen index does not consider the returns per unit of systematic risk.

Empirical results have indicated that the return distributions of mutual funds are not normally distributed. Additionally, return distributions also have the leptokurtic and fat tail problems, which need to be modified. Therefore, recent developments in the use of VaR as a measure of market risk volatility have been proposed to overcome these problems. For example, Dowd (1999) and Campbell et al. (2001) introduced VaR into the Sharpe index by replacing standard deviation with VaR to evaluate the performance of portfolios. Alexander and Baptista (2003) modified the bias of the Sharpe ratio by using reward-to-VaR ratio. Moreover, Eling and Schuhmacher (2007) proposed the use of a VaR-based measure in the performance evaluation that is closely related to the widely used Sharpe ratio. Therefore, VaR can be used as a tool to evaluate the performance of a portfolio.

In order to more accurately evaluate the performance of a portfolio and to fulfill risk management needs, Matten (2000) proposed risk adjusted performance measures (RAPM) based on the Sharpe ratio to describe capital allocation procedures. RAPM use the concept of VaR to derive the risk-adjusted return on capital, which is used by fund managers to rank and compare portfolio performance. Since Bankers Trust uses capital at risk (CaR) as an adjustment to return on capital to propose risk-adjusted return on capital (RAROC), RAROC has become the most popular method for performance evaluation. RAROC is based on the idea that the allocated equity capital of a business unit should equal its $\mathrm{CaR}$, used to allocate capital for risk management and performance evaluation. RAROC also serves as a business decision-making model. It uses VaR as a risk measure, providing more objective and more accurate evaluation of fund performance. Like the Sharpe ratio, RAROC is used to measure the return per unit of risk. However, the biggest difference is that the Sharpe ratio uses standard deviation as a risk measure and RAROC uses VaR as return-adjusted risk. Chen and Yang (2002) and Qian and Li (2007) indicated that the RAROC approach could describe the China's mutual fund performance more exactly. Even though there were some recent studies on the Taiwan's mutual funds performance evaluation issues, such as Chen et al. (2011) and Zhao et al. (2011). However, there were no past studies being published for evaluating equity mutual fund performance in Taiwan, based on RAROC approach. Therefore, this study takes into account both risk and return, with a RAROC as an indicator for evaluation of fund performance.

In order to judge whether past performance can be used to predict future fund performance, we tested the persistence of mutual fund performance. In the early 1960s, scholars started to study the persistence of mutual fund performance, e.g., Sharpe (1966), Jensen (1968) and Carlson (1970), but their findings have not supported the persistence of fund performance. In the late 1980s and 1990s, some evidence supporting the persistence of fund performance gradually appeared. For example, Grinblatt and Titman (1992) and Elton et al. (1993) reported persistence in mutual fund returns over periods of five to ten years. Moreover, Hendricks et al. (1993) found that the performance of mutual 
funds persists in the short-term rather than long-term. Other studies, such as Bauer et al. (2006) and Keswani and Stolin (2008) found evidence of the persistence in mutual fund performance over short-term horizons of one to three years. However, Rhodes (2000) and Dimson and Minio-Kozerski (2001) reported non-persistence in mutual fund performance. A review of previous studies shows that the results on the persistence of performance in mutual funds are still very inconsistent. Previous studies investigating performance persistence have focused on performance persistence in different countries or in diverse time periods.

In Taiwan, there were few studies on the mutual funds performance persistence issues. For example, Hsu and Lin (2007) using data envelopment analysis (DEA) to measure the performance of Taiwan domestic equity funds, and tested the performance persistence. It showed that the different results in performance persistence the different results in performance persistence analyses between DEA and Sharpe measures. However, little attention had been focused on issues concerning the equity mutual fund performance persistence measures from bull to bear market in Taiwan.

In summary, the main purpose of this study is to establish a mutual fund performance evaluation indicator, enable investors to make the right investment decisions when facing a climate change in the investment market. The empirical results also provide to direct investors and fund managers to minimize the risk of their investments.

\section{Classical Measures of Mutual Fund Performance}

In this article, two of the most widely used traditional methods of measuring performance, namely the Sharpe ratio and Treynor ratio are adopted as follows (Gallo, 2008).

Sharpe (1966) asserted that mutual funds cannot fully distribute non-systematic risk. Therefore, mutual fund performance evaluation should be based on the adjustment of the excess return on the portfolio under consideration of total risk as a performance measure. Using the standard deviation of portfolio return to represent total risk, evaluation also includes systematic risk and non-systematic risk. According to the above concepts, Sharpe proposed the idea of the Sharpe ratio. The definition of Sharpe ratio $S_{P}$ is as follows:

$$
S_{p}=\frac{R_{p}-R_{f}}{\sigma_{p}},
$$

where $S_{p}$ is Sharpe's ratio for fund $p, R_{p}$ is the average return on fund $p, R_{f}$ is the return on risk free assets, and $\sigma_{p}$ is the standard deviation of return on fund $p$. The higher the $\sigma_{P}$, the greater the variability of the portfolio. The lower volatility will have a higher Sharpe ratio. Hence, a higher Sharpe ratio indicates a better fund performance than a lower ratio.

Treynor (1965) pointed out that there is a relationship between portfolio return and risk. Treynor used the concept of the characteristic line to partition stock market returns into systematic and non-systematic risk. The slope of a characteristic line is the beta (systematic risk) that measures the relative volatility of mutual fund returns. The higher the slope, the higher the volatility is, and vice versa. Treynor assumed that a mutual fund is a completely diversified portfolio. Thus, it does not contain any non-systematic risk. When measuring the performance of mutual funds, the beta coefficient is used to adjust the excess returns and obtain the Treynor ratio as follows:

$$
T_{p}=\frac{R_{p}-R_{f}}{\beta_{p}},
$$

where $T_{p}$ is Treynor's ratio for fund $p, R_{p}$ is the average return on fund $p, R_{f}$ is the return on risk free assets, and $\beta_{p}$ is sensitivity of fund return to market return. When the Treynor index larger that the better performance of the fund, and vice versa.

\section{Risk-Adjusted Performance Measurement}

\subsection{Value at Risk Measure}

VaR is defined as the maximum possible loss for a given asset portfolio under normal market volatility. To measure VaR, Beder (1995) and Hendricks (1996) pointed out that there are too many different ways to calculate VaR and no single VaR measurement can be recommended. Hence, when estimating VaR, the choice of model and its assumptions must be carefully considered. Otherwise, the same estimation method can lead to completely different results. In this study, calculation of VaR was based on the variance-covariance (VC) approach (Jorion, 2007). Therefore, a mutual fund's VaR can be expressed as

$$
\operatorname{VaR}=-W Z_{\alpha} \sigma_{R} \sqrt{T}
$$

where $W$ is a scale parameter reflecting the overall size of the portfolio, $Z_{\alpha}$ is the critical value from the normal 
distribution for probability $(1-\alpha)$ (if the VaR is predicated at a confidence level of $95 \%$, then $Z_{\alpha}=-1.645$ ), $\sigma_{R}$ is the standard deviation of the rate of return of the portfolio, and $T$ is the holding period.

As mentioned in a previous study, there are three existing methods to calculate a mutual fund's VaR: the variance-covariance approach, the historical simulation approach and the Monte Carlo simulation approach (Blanco, 2001; Jorion, 1997). For example, Hendricks (1996) calculated VaR measures using the equally weighted moving average approach and the historical simulation approach to evaluate the performance of portfolios. Bredin and Hyde (2004) measured and evaluated the VaR performance a foreign exchange portfolio by using the standard variance covariance approach, historical simulation approach, orthogonal GARCH and exponentially weighted moving average.

Based on the findings of the studies mentioned above, the variance-covariance approach and the historical simulation were selected to estimate $\mathrm{VaR}$ in this study. The general algorithms of the two methods are described as follows:

\section{(1) Variance-covariance approach}

The variance-covariance approach can be calculated in a number of ways, but the variance-covariance matrix is one of the common techniques used to calculate VaR. It is a kind of parametric approach. Harris and Yilmaz (2010) mentioned that there are a number of models for estimating the variance-covariance matrix, including EWMA and GARCH. A number of studies, such as Brailsford and Faff (1996), Walsh and Tsou (1998) and Best (1999), have all suggested that the EWMA and GARCH models are successful at forecasting the volatility in the financial markets. Therefore, this article used the equally weighed moving average approach, EWMA and GARCH to estimate the variance-covariance matrix then derived the VaR, as described below:

(a) Equally weighted moving average approach

The equally weighted moving average approach (i.e. simple moving average model; SMA) uses a set of historical data for an observation period with a fixed length to estimate the variance-covariance matrix. Consider a sample of $T$ historical data of daily returns $r_{t}$. An estimate of the variance of daily returns is given by

(b) Exponentially weighted moving average model

$$
\sigma_{t}^{2}=\left(\sum_{k=1}^{T} r_{t-k}^{2}\right)
$$

The EWMA approach used by J.P. Morgan's RiskMetrics methodology is quite acceptable for calculating VaR. A feature of this method is that it assigns different weights to each of the data points. The model is given by the following expression:

$$
\sigma_{t}^{2}=\lambda \sigma_{t-1}^{2}+(1-\lambda) r_{t-1}^{2},
$$

where $\sigma_{t}^{2}$ is the variance rate for day $t, r_{t}$ is the continuously compounded return for day $t, \lambda$ is the decay factor and $0<\lambda<1$. In practice, the values recommended by RiskMetrics approach are 0.94 for daily data and 0.97 for monthly data (RiskMetrics, 1996). Both of they are inconsistent, but they are easy to use. And approximate the behavior of actual data quite well (Jorion, 2001).

\section{(C) GARCH model}

Because of the return of financial assets displays volatility clustering, therefore, we need to calculate the volatility of the return in order to estimate the VaR. There are many ways of calculating volatility, such as implied volatility, historical volatility and Monte Carlo simulations. One of the simplest and most commonly used ways to calculate volatility is the GARCH model. Engle (1982) modeled time varying conditional volatility with the autoregressive conditional heteroskedasticity (ARCH) model. Bollerslev (1986) extended this method to the GARCH (generalized ARCH) model, and suggested that the GARCH model can explain and describe the phenomenon of volatility clustering in returns. There are many different types of GARCH models. Most empirical studies, such as Engle et al. (1991), West et al. (1993) and Colm and Patton (2000) have indicated that the GARCH(1,1) model provides a good fit to time series data. Bollerslev et al. (1992) found that the $\mathrm{GARCH}(1,1)$ model could fit financial return data well. And the GARCH(1,1) model is by far the most widely used of the GARCH models (Chen and Yang, 2002). Therefore, we used the GARCH$(1,1)$ model in the study. The GARCH $(1,1)$ model for daily returns of equity mutual fund markets is defined as:

$$
\begin{gathered}
r_{t}=\sigma_{t} \varepsilon_{t}, \quad \varepsilon_{t} \sim N(0,1), \\
\sigma_{t}^{2}=\omega+\alpha r_{t-1}^{2}+\beta \sigma_{t-1}^{2},
\end{gathered}
$$

where $0<\omega \leq \infty, \alpha \geq 0, \beta \geq 0$ and $\alpha+\beta<1, r_{t}$ is the continuously compounded return for day $t$. 


\subsection{RAROC Based on VaR Measures}

The concept of RAROC was first developed by Bankers Trust in the 1970s and can be used for capital allocation and performance evaluation. Both risk and return characteristics can be taken into account. This is one of the advantages of using RAROC as a management tool. Therefore, as a key part of RAROC, the potential losses from business activities are taken as the VaR. In general, the higher the risk is, the higher the return is. However, if the expected return is constant, higher risk will lead to a lower RAROC. This tool helps businesses or individuals to find a balance between risk and return on investment.

Shearer and Forest (1998) pointed out that RAROC is widely used in practice, because (1) it combines the concept of risk adjustment and capital allocation. (2) RAROC is based on the company's returns and the cost of capital to evaluate the company's performance. (3) The calculation of RAROC is relatively simple. Zaik et al. (1996) and Crouhy et al. (1999) proposed that top management of banks should apply RAROC to evaluate business portfolios and make efficient resource allocation decisions to improve the banks' risk and return. Culp (2001) pointed out that ex-ante RAROC can be used for allocation of capital to businesses, and ex-post RAROC can be used for performance evaluation. Therefore, RAROC is not only valuable for risk-adjusted performance evaluation, but it has also become an effective tool for capital allocation purposes.

RAROC is similar to the Sharpe ratio in that is evaluates the performance and portfolios of risky assets. The two indicators take the expected return per unit of risk into account. The difference is that RAROC uses VaR to measure the market risk, while Sharpe ratio measures market risk based on standard deviation. A number of different ways have been developed to calculate RAROC (Culp, 2001; Prokopczuk et al., 2007), but Matten (2000) pointed out that there is no standard formula for estimating RAROC. We introduce a general RAROC concept (Prokopczuk et al., 2007) and define RAROC as RAROC = Expected return / Economic capital. Economic capital is attributed on the basis of three risk factors: market risk, credit risk, and operational risk, and often calculated by VaR (Jorion, 2001). Therefore, we define the RAROC as:

$$
\text { RAROC }=\text { Expected Return } / \mathrm{VaR} \text {. }
$$

In general, higher RAROC is always better. However, higher RAROC does not necessarily mean that the investment is also profitable (Prokopczuk et al., 2007); it only means that there is a good portfolio performance. Therefore, this article simultaneously considers risks and returns by constructing a VaR-RAROC model for mutual fund performance evaluation.

Different VaR estimation methods have a significant impact on RAROC. Therefore, this study estimated VaR by constructing three VaR-RAROC models. When the VaR-RAROC models constructed by the VaR measures were obtained by SMA, EWMA, and GARCH $(1,1)$, this study refers to the above approaches as the SRAROC, ERAROC and GRAROC models, respectively.

\subsection{Historical Simulation Approach}

The most widely used non parametric approach is the historical simulation approach (Bredin and Hyde, 2004). The historical simulation approach calculates a portfolio's VaR using historical return data. It assumes that the realized historical returns are a good guide for prediction of future returns. According to the required confidence level, it uses the corresponding percentiles of the observation period as VaR measures.

One of the advantages of the historical simulation approach is that it is nonparametric. This is because there is no need to make any assumption about the distribution of the risk factors. This approach can easily solve the problems of fat tails and skewness (Jorion, 2007). In addition, it is simple and easy to implement. The historical simulation approach also has limitations, such as: (1) a large amount of historical data is required; (2) it assumes that the future is sufficiently like the past, leading to distortions in the estimation of VaR (Dowd, 1998); (3) there is a dilemma when determining the length of the historical observation period. Based on the findings of Bali and Cakici (2004), we used the historical simulation method to estimate VaR. Therefore, when the VaR measures were obtained by the historical simulation method, this study referred to this approach as the HRAROC model.

\subsection{The Spearman Rank Correlation Test}

In order to evaluate the consistency and persistence of the result of mutual fund performance evaluation, rank correlations between the bull and the bear market periods were calculated. The two-tailed Spearman rank correlation test was used to test for the significance of the correlations (see Brorsen and Harri (2004)). The Spearman rank correlation coefficient $\gamma_{S}$ is defined as $\gamma_{S}=1-\left(6 \sum d^{2}\right) /\left[n\left(n^{2}-1\right)\right]$, where $\sum d^{2}$ is the sum of the squared differences of ranks over two consecutive years for all funds and $n$ is the number of funds. The $\gamma_{S}$ value always falls between -1 and +1 . 


\section{Empirical Analysis}

\subsection{Data and Descriptive Statistics}

In order to verify open-end equity mutual fund performance and persistence in Taiwan during changes in market climate, the 2007 financial crisis (Derbel et al., 2011) provides a suitable environment to conduct empirical research. This study evaluated the performance of equity mutual funds during the period from November 1, 2006 to October 31, 2008 (500 dealing days), with an emphasis on the 2007 financial crisis. These periods contain both bull and bear market periods and are appropriate for investigating the impact of market climate on performance measures.

Before the crisis, Taiwan's stock market was in a bull market from November 2006 to October 2007. In this period, the Taiwan Stock Exchange Capitalization Weighted Stock Index (TAIEX) increased from 7013.99 to 9711.37. As the financial crisis occurred, the market quickly dropped after that. By the end of our sample period, the index was around 4870.66. Therefore, we divided our sample into a bull market and a bear market periods using October 31, 2007 as the cutting point.

Therefore, two sample periods were used for testing. The first sample period was publicly available data from the period from November 1, 2006 to October 31, 2007, which included 250 bull days. The second sample period was from the period from November 1, 2007 to October 31, 2008, which included 250 bear days.

We used the domestic open-end equity mutual funds in Taiwan for our empirical tests. In order to examine if there was persistence in funds performance, it was necessary to limit the study to funds that closed between 2002 and 2010. Therefore, the final sample consisted of top 30 open-stock mutual funds that chose from the cumulative performance.

The data of the daily net assets value (NAV) of the mutual funds were collected from the Taiwan Economic Journal database. The daily returns for mutual funds were calculated as follows: Return ${ }_{t}=\left(\mathrm{NAV}_{t}-\mathrm{NAV}_{t-1}\right) / \mathrm{NAV}_{t-1}$. Table 1 provides descriptive statistics for both the bull and bear market periods.

Table 1 provides descriptive statistics for the both bull and bear market periods. Table 1 show that in the bull (bear) market period, the mean returns of mutual funds are all positive (negative). The skewness value in addition to Fund 9, 24, and 26 for the right-skewness in the bear market period, and the remaining funds are all left-skewed. Most of kurtosis greater than 3 shows the characteristics of a fat-tailed and leptokurtic.

\subsection{Results of Mutual Fund Performance Evaluation}

\subsubsection{Results of the Classical Performance Measures}

To analyze classical performance measures, this article used the Sharpe and Treynor ratios to evaluate the performance of equity mutual funds in Taiwan. The higher the ratio, the better the performance of the investment. Table 2 shows the values and rankings obtained by the Sharpe and Treynor ratios for the 30 funds during both bull and bear market periods. The Sharpe ratio of the active funds in the bull and bear periods ranged from 0.26 to 0.81 and -0.7 to -0.47 , respectively. Treynor's ratio in the bull and bear periods ranged from 1.4 to 5.87 and -6.95 to -4.49 , respectively. In a bull market, average mutual fund excess returns would be positive (Table 1), and the risk-adjusted return measure would decrease as risk increased. However, in a bear market period, average mutual fund excess returns would be negative (Table 1), the risk-adjusted return measure would become increase as risk increased. Therefore, we obtain the positive (negative) ratios in the bull (bear) market period. The rankings achieved by the Sharpe and Treynor ratios were essentially different during bull and bear market periods. Moreover, the Sharpe and Treynor ratios changed from positive to negative upon encountering changes in the market climate.

\subsubsection{Results for the SRAROC and ERAROC Models}

In this study, we exploited the SRAROC model to evaluate mutual fund performance. According to Eq. (4), we estimated the variance rate for day $t$ and substituted the result into Eq. (6) to obtain the VaR. We used VaR to measure diversified economic capital, and then we were able to compute the VaR-RAROC. Table 3 shows the values of SRAROC and the rankings in both the bull and bear market periods.

Next we estimated VaR using the exponentially weighted moving average (EWMA) variance covariance approach (Eq. (3)). Two fixed decay factors were used, including $\lambda=0.94$ and $\lambda=0.97$. We substituted VaR into RAROC (Eq. (8)) to calculate the $\operatorname{ERAROC}(\lambda=0.94)$ and $\operatorname{ERAROC}(\lambda=0.97)$. Table 3 shows the values of $\operatorname{ERAROC}(\lambda$ $=0.94)$ and $\operatorname{ERAROC}(\lambda=0.97)$ in both bull and bear market periods.

Table 3 shows that when the market climate changed from bull to bear, the SRAROC, ERAROC $(\lambda=0.94)$ and $\operatorname{ERAROC}(\lambda=0.97)$ values changed from positive to negative. The performing ranking showed a significant 
difference in both bull and bear markets.

\subsubsection{Results for the GRAROC Model}

In this study, the GARCH $(1,1)$ model was also used to capture the volatility of returns. Before the analysis, we first had to understand whether the given variables exhibited stationarity. In this study, an Augmented Dickey-Fuller (ADF) test was used to determine whether a variable exhibits stationarity. When the data are stationary, in this study, the Engle's (1982) Lagrange Multiplier (LM) test was used for testing the ARCH effects. If returns were found to be highly significant based on ARCH effects, it was appropriate to use GARCH models. The results of the ARCH LM test show that all daily return series exhibit statistically significant ARCH effects at the $95 \%$ level of confidence. It was appropriate to use GARCH models to estimate the levels of volatility.

According to Eq. (7), when using the maximum likelihood test to estimate parameters $\omega, \alpha$ and $\beta$, and substituting the results into Eq. (7), the conditional variance can be obtained. Then, by substituting conditional variance into Eq. (3), VaR (95\% confidence level) can be obtained. Substituting the VaR into the RAROC formula can obtain the GRAROC value. Table 4 shows the values and rankings obtained by the GRAROC model. The performance rankings of the mutual funds in the bull and bear market periods seem to change only slightly (Table 4). Only a few funds have slightly different ranks.

\subsubsection{Results for the HRAROC Model}

When using the historic simulation method, the optimum length of the history data window must be determined before calculating VaR. The Basel Committee suggested that the period of historical data should be 3 to 5 years, or more. Therefore, this study used a 1,250 day period (five years), and the sample data is divided into two sub-periods: November 1, 2002 until October 31, 2007 for the bull market period and November 1, 2003 until October 31, 2008 for the bear market period. Using series of historical prices over the past five years to calculate the price return, by sorting the percentile $(\alpha=5 \%)$ from small to large to calculate a specific confidence level, we obtained $95 \%$ confidence VaR. By substituting VaR into the RAROC formula, we then can obtain the value of the HRAROC model, as shown in Table 4. Table 4 shows the values and rankings obtained by the HRAROC model. The performance rankings of mutual funds obtained by the HRAROC model in the bull and bear market periods seem different (Table 4).

\subsection{Results of Consistency and Persistence in Bull and Bear Markets}

For performance consistency and persistence, the Spearman rank correlation coefficient was used as the test statistic. The Spearman's rank correlation coefficient for the rankings of fund performances was computed by using the Sharpe ratio, Treynor ratio, SRAROC, ERAROC $(\lambda=0.94)$, ERAROC $(\lambda=0.97)$, GRAROC and HRAROC models.

\subsubsection{Relationships between Performance Measures}

As part of performance evaluation, it is interesting to explore the relationships between different performance measures in bull and bear market periods. Therefore, we examined the consistency of different performance measures using the Spearman rank correlation test. Higher Spearman correlation coefficient values represent higher levels of internal consistency. Table 5 shows the Spearman's rank correlation coefficients for the different performance measures in both bull and bear market periods.

The results show that the bull market period has a higher correlation value than the bear market period does. In the bull market period, there was a high correlation (more than 0.7 ) between performance measures, except for the relationship of the Sharpe ratio and the HRAROC model. In the bear market period, we found that the rank correlations of the HRAROC, Treynor ratio and ERAROC measures were relatively low $(0.48,0.36$ and 0.49$)$. In addition, the correlation coefficient among the different performance measures fell between 0.55 and 0.97 . Not surprisingly, the Spearman correlations of the Sharpe and Treynor ratios in both bull and bear market periods were rather high with 0.81 and 0.86 . That is because in a well-diversified portfolio, the non-systematic risk and the systemic risk tend to similar degree. Thus, the standard deviation $(\sigma)$ and beta $(\beta)$ of return on a mutual fund are not change too much. We will get the similar result. These findings provide an evidence of the relationship between different performance measures when the performance measure is not rigorously selected.

\subsubsection{Results of Persistence in the Bull and Bear Periods}

After measuring the performance of all funds, we ranked the measurement values and tested the rank correlations in different investment market climates. In this study, our evaluation period started in November 2006 and ended in October 2008. These periods contained both bull (November 2006 to October 2007) and bear (November 2007 to October 2008) market periods and were appropriate for investigating the impact of market climate on mutual fund performance measures. We calculated the Spearman rank correlation coefficients in the bull and the bear market 
periods to test persistence. The aim is to investigate if high performance rankings in bull market period forecast high rankings for the bear market period.

Table 6 reports the persistence results using different performance measures. A significant positive correlation between past performance and future performance denotes performance persistence. The two-tailed Spearman tests based on decile rankings were significant for the SRAROC, GRAROC and HRAROC models for correlations of $0.563,0.702$, and 0.450 , respectively. Consequently, using these three approaches we find persistence of performance. Therefore, the applications of RAROC approach in funds performance evaluation that will lead fund managers and analyses towards the achievement persistence. Low significance and insignificant correlation coefficients indicate that classical indicators of performance persistence do not exist in our sample. Therefore, these classical indicators are not quite suitable for use as the indicator for the evaluation of the fund's performance, because it can't manage the mutual fund risk behavior during periods of high volatility. However, it's clear that classical indicators couldn't forecast future performance better than VaR-RAROC models. In addition, the GRAROC model showed the highest degree of significance at 0.01 confidence level in the Spearman rank correlation test. This result indicates that performance measures could indicate fund's performance in bear market period based on the performance in bull market period. Therefore, when the market climate shifts from bull market to bear market, we found the result of the GRAROC model shows a strong persistence of the performance. From the above empirical analysis results, in face of market climate change, we see that using the VaR based RAROC method to evaluate the performance of open-end funds yielded more stronger persistence than the traditional methods.

\section{Conclusion}

This study investigates the performance of 30 Taiwan open-end equity mutual funds, and the sample period was divided into two sub-periods, the bull market period (November 2006 to October 2007) and the bear market period (November 2007 to October 2008). By using Sharpe ratio, Treynor ratio, SRAROC, ERAROC, GRAROC and HRAROC models as the indicators of performance evaluation, we tested consistency and persistence in bull and bear market situations.

The analysis of performance evaluation used six indicators to rank the equity mutual funds with positive (negative) performance in the bull (bear) market. The conclusion is consistent with the evidence reported in Ennis and Sebastian (2003). Moreover, most of the mutual funds performance rankings are inconsistent for both bull and bear market periods.

We used the Spearman rank coefficient to find out the relationships among the six performance indicators in the bull (bear) market. All Spearman rank correlation coefficients suggest a positive correlation, and the confidence level for the correlation is significant. We also noted that the Sharpe and Treynor ratios rankings show a strong positive correlation. Our findings are similar to the findings of Bal and Leger (1996) and Casarin et al. (2005) which indicated a very high correlation between the Sharpe and Treynor ratios.

According to the results, based on Sharpe ratio and Treynor ratio, there was some evidence of performance persistence in the bull and bear markets. However, this evidence was not statistically significant. Strong evidence shows performance persistence, based on SRAROC, GRAROC and HRAROC models, and there is a high confidence level, implying statistical significance. In addition, we found that the GRAROC model showed the highest level of persistence. Therefore, this article suggests that when investors are making investment decisions, they should consider the investment market climate, and using GRAROC model as an indicator of equity mutual fund performance to reduce investment risk.

This article found that when a sudden change in investment market climate occurs, traditional performance measurement indicators for mutual fund selection may not be good indicators of future performance. Therefore, we recommend that investors use the GARCH model to capture the volatility of the financial markets. To attain good performance in mutual fund selection, investors calculate the VaR and construct a RAROC based VaR model as a fund performance evaluation indicator. The proposed model was successfully applied to test a mutual fund's consistency and persistence of performance. However, further research will be required to identify whether this finding can be extrapolated to other markets.

\section{References}

Alexander, G.J., \& Baptista, A.M. (2003). Portfolio Performance Evaluation Using Value at Risk. Journal of Portfolio Management, 29, 93-102. http://dx.doi.org/10.3905/jpm.2003.319898.

Bal, Y., \& Leger, L.A. (1996). The Performance of UK Investment Trusts. Service Industries Journal, 16, 67-81. http://dx.doi.org/10.1080/02642069600000007.

Bali, T.G., \& Cakici, N. (2004). Value at Risk and Expected Stock Returns. Financial Analysts Journal, 60, 57-73. 
http://dx.doi.org/10.2469/faj.v60.n2.2610.

Bauer, R., Otten, R., \& Rad, A.T. (2006). New Zealand Mutual Funds: Measuring Performance and Persistence in Performance. Accounting \& Finance, 46, 347-363. http://dx.doi.org/10.1111/j.1467-629X.2006.00171.x.

Beder, T.S. (1995). VaR: Seductive but Dangerous. Financial Analysts Journal, 51, 12-24. http://dx.doi.org/10.2469/faj.v51.n5.1932.

Best, P. (1999). Implementing Value at Risk, England: John Wiley \& Sons.

Blanco, C. (2001). Calculating and Using Value-at-Risk. Risk Management, 3, 13-15, http://dx.doi.org/10.1057/rm.2009.4.

Bollerslev, T. (1986). Generalized Autoregressive Conditional Heteroskedasticity. Journal of Econometrics, 31, 307-327. http://dx.doi.org/10.1016/0304-4076(86)90063-1.

Bollerslev, T., Chou, R.Y. \& Kroner, K.F. (1992). ARCH Modeling in Finance: A Review of the Theory and Empirical Evidence. Journal of Econometrics, 52, 5-59. http://dx.doi.org/10.1016/0304-4076(92)90064-X.

Brailsford, T.J., \& Faff, R.W. (1996). An Evaluation of Volatility Forecasting Techniques. Journal of Banking \& Finance, 20, 419-438. http://dx.doi.org/10.1016/0378-4266(95)00015-1.

Bredin, D., \& Hyde, S. (2004). FOREX Risk: Measurement and Evaluation Using Value-at-Risk, Journal of Business Finance \& Accounting, 31, 1389-1417. http://dx.doi.org/10.1111/j.0306-686X.2004.00578.x.

Brorsen, B.W., \& Harri, A. (2004). Performance Persistence and the Source of Returns for Hedge Funds. Applied Financial Economics, 14, 131-141. http://dx.doi.org/10.1080/0960310042000176407.

Campbell, R., Huisman, R., \& Koedijk, K. (2001). Optimal Portfolio Selection in a Value-at-Risk Framework. Journal of Banking \& Finance, 25, 1789-1804. http://dx.doi.org/10.1016/S0378-4266(00)00160-6.

Carlson, R.S. (1970). Aggregate Performance of Mutual Funds, 1948-1967. Journal of Financial and Quantitative Analysis, 5, 1-32. http://dx.doi.org/10.2307/2979005.

Casarin, R., Lazzarin, M., Pelizzon, L., \& Sartore, D. (2005). Relative Benchmark Rating and Persistence Analysis: Evidence from Italian Equity Funds. European Journal of Finance, 11, 297-308. http://dx.doi.org/10.1080/1351847042000286658.

Chang, C.H., Lin, J.J., Lin, J.H., \& Chiang, M.C. (2010). Domestic open-end equity mutual fund performance evaluation using extended TOPSIS method with different distance approaches. Expert Systems with Applications, 37, 4642-4649. http://dx.doi.org/10.1016/j.eswa.2009.12.044.

Chen, L.H., \& Huang, L. (2009). Portfolio Optimization of Equity Mutual Funds with Fuzzy Return Rates and Risks. Expert Systems with Applications, 36, 3720-3727. http://dx.doi.org/10.1016/j.eswa.2008.02.027.

Chen, X., \& Yang, H. (2002). RAROC Approach and Funds Performance Evaluation. South China Financial Research, 17, 33-37. http://dx.doi.org/ cnki:ISSN:1008-5742.0.2002-06-008.

Chen, Y., Chiu, Y., \& Li, M. (2011). Mutual Fund Performance Evaluation-Application of System BCC Model. South African Journal of Economics, 79, 1-16. http://dx.doi.org/10.1111/j.1813-6982.2011.01263.x.

Colm, K., \& Patton, A.J. (2000). Multivariate GARCH Modeling of Exchange Volatility Transmission in the European Monetary System. Financial Review, 35, 29-48. http://dx.doi.org/10.1111/j.1540-6288.2000.tb01405.x.

Crouhy, T., Turnbull, S.M., \& Wakeman, L.M. (1999). Measuring Risk-Adjusted Performance. Journal of Risk, 2, 5-35.

Culp, C.L. (2001). The Risk Management Process: Business Strategy and Tactics, New York: John Wiley \& Sons.

Derbel, H., Bouraoui, T., \& Dammak, N. (2011). Can Islamic Finance Constitute a Solution to Crisis? International Journal of Economics and Finance, 3, 75-83. http://dx.doi.org/10.5539/ijef.v3n3p75.

Dimson, E., \& Minio-Kozerski, C. (2001). The Closed-End Fund Discount and Performance Persistence, Working Paper: London Business School.

Dowd, K. (1998). Beyond Value at Risk, New York: John Wiley \& Sons.

Dowd, K. (1999). A Value at Risk Approach to Risk-Return Analysis. Journal of Portfolio Management, 25, 60-67. http://dx.doi.org/10.3905/jpm.1999.319755.

Eling, M., \& Schuhmacher, F. (2007). Does the Choice of Performance Measure Influence the Evaluation of Hedge Funds? Journal of Banking \& Finance, 31, 2632-2647. http://dx.doi.org/10.1016/j.jbankfin.2006.09.015. 
Elton, E.J., Gruber, M.J., Das, S., \& Hlavka, M. (1993). Efficiency with Costly Information: A Reinterpretation of Evidence from Managed Portfolios. Review of Financial Studies, 6, 1-22. http://dx.doi.org/10.1093/rfs/6.1.1.

Engle, R.F. (1982). Autoregressive Conditional Heteroscedasticity with Estimates of the Variance of United Kingdom Inflation. Econometrica, 50, 987-1007. http://dx.doi.org/10.2307/1912773.

Engle, R.F., Hong, T., Kane, A., \& Noh, J. (1991). Aribitration Valuation of Variance of United Kingdom Inflation, Advances in Futures and Options Research, 55, 425-442.

Ennis, R.M., \& Sebastian, M.D. (2003). A Critical Look at the Case for Hedge Funds: Lessons from the Bubble. Journal of Portfolio Management, 29, 103-112. http://dx.doi.org/10.3905/jpm.2003.319899.

Gallo, A. (2008). The Performance of Pension Funds: The Case of Italy. Investment Management and Financial Innovations, $\quad 5, \quad 25-32 . \quad$ [Online] Available: http://www.businessperspectives.org/journals_free/imfi/2008/imfi_en_2008_04_Gallo.pdf.

Goltz, F., \& Schroeder, D. (2008). Hedge Fund Reporting Survey, Nice: EDHEC Risk and Asset Management Research Centre.

Grinblatt, M., \& Titman, S. (1992). Performance Persistence in Mutual Funds. Journal of Finance, 47, 1977-1984. http://dx.doi.org/10.2307/2329005.

Harris, R.D.F., \& Yilmaz, F. (2010). Estimation of the Conditional Variance-Covariance Matrix of Returns Using the Intraday Range. International Journal of Forecasting. 26, 180-194. http://dx.doi.org/10.1016/j.ijforecast.2009.02.009.

Hendricks, D. (1996). Evaluation of Value-at-Risk Models Using Historical Data, Economic Policy Review, 2, 39-69. [Online] Available: http://ssrn.com/abstract=1028807.

Hendricks, D., Patel, J., \& Zeckhauser, R. (1993). Hot Hands in Mutual Funds: Short-Run Persistence of Performance, 1974-88. Journal of Finance, 48, 93-130. http://dx.doi.org/10.2307/2328883.

Hsu, C.S., \& Lin, J.R. (2007). Mutual Fund Performance and Persistence in Taiwan: A Non-Parametric Approach. Service Industries Journal, 27, 509-523. http://dx.doi.org/10.1080/02642060701411658.

Israelsen, C.L. (2005). A Refinement to the Sharpe Ratio and Information Ratio. Journal of Asset Management, 5, 423-427. http://dx.doi.org/10.1057/palgrave.jam.2240158.

Jensen, M.C. (1968). The Performance of Mutual Funds in the Period 1945-1964. Journal of Finance, 23, 389-416. http://dx.doi.org/10.2307/2325404.

Jorion, P. (1997). Value at Risk: The New Benchmark for Controlling Market Risk, New York: McGraw-Hill.

Jorion, P. (2001). Value at Risk: the New Benchmark for Managing Financial Risk, McGraw-Hill New York.

Jorion, P. (2007). Value at Risk: The New Benchmark for Managing Financial Risk, Chicago: McGraw-Hill.

Keswani, A., \& Stolin, D. (2008). Which Money is Smart? Mutual Fund Buys and Sells of Individual and Institutional Investors. Journal of Finance, 63, 85-118. http://dx.doi.org/10.1111/j.1540-6261.2008.01311.x.

Lin, M.C., \& Chen M. (2008). The Profitability of the Weekend Effect: Evidence. From the Taiwan Mutual Fund Market. Journal of Marine Science and Technology, 16, 222-233. [Online] Available: http://jmst.ntou.edu.tw/marine/16-3/222-233.pdf.

Matten, C. (2000). Managing Bank Capital: Capital Allocation and Performance Measurement, England: John Wiley \& Sons.

Prokopczuk, M., Rachev, S.T., Schindlmayr, G., \& Trueck, S. (2007). Quantifying Risk in the Electricity Business: A RAROC-Based Approach. Energy Economics, 29, 1033-1049. http://dx.doi.org/10.1016/j.eneco.2006.08.006.

Qian, P.F., \& Li, K. (2007). An Assessment of Fund Performance with RAROC Index Based on VaR. Commercial Research, 11, 30-39. http://dx.doi.org/ CNKI:SUN:BUSI.0.2007-11-059.

Rhodes, M. (2000). Past Imperfect? The Performance of UK Equity Managed Funds. Financial Services Authority Occasional Paper, 9, 1-58. http://dx.doi.org/10.2139/ssrn.428001.

RiskMetrics. ${ }^{T M}$ (1996). Technical Document, New York: J.P. Morgan.

Scholz, H. (2006). Refinements to the Sharpe Ratio: Comparing Alternatives for Bear Markets. Journal of Asset Management, 7, 347-357. http://dx.doi.org/10.1057/palgrave.jam.2250040.

Sharpe, W. F. (1966). Mutual Fund Performance, Journal of Business, 39, 119-138. 
http://dx.doi.org/10.1086/294846.

Shearer, A.T., \& Forest, L.R. (1998). Improving Quantification of Risk-Adjusted Performance within Financial Institutions. Commercial Lending Review, 13, 48-48.

Treynor, J.L. (1965). How to Rate Management of Investment Funds, Harvard Business Review 43, 63-75.

Walsh, D.M., \& Tsou, G.Y.G. (1998). Forecasting Index Volatility: Sampling Interval and Non-Trading Effects. Applied Financial Economics, 8, 477-485. http://dx.doi.org/10.1080/096031098332772.

West, K.D., Edison, H.J., \& Cho, D. (1993). A Utility Based Comparison of Some Models of Exchange Rate Volatility. Journal of International Economics, 35, 23-45. http://dx.doi.org/10.1016/0022-1996(93)90003-G.

Zaik, E., Walter, J., Retting, G., \& James, C. (1996). RAROC at Bank of America: From Theory to Practice. Journal of Applied Corporate Finance, 9, 83-93. doi:10.1111/j.1745-6622.1996.tb00117.x, http://dx.doi.org/10.1111/j.1745-6622.1996.tb00117.x.

Zhao, X., Wang, S., \& Lai, K.K. (2011). Mutual Funds Performance Evaluation Based on Endogenous Benchmarks. Expert Systems with Applications, 38, 3663-3670. http://dx.doi.org/10.1016/j.eswa.2010.09.022.

Table 1. Descriptive statistics

\begin{tabular}{|c|c|c|c|c|c|c|c|c|c|c|c|c|}
\hline \multirow{2}{*}{$\begin{array}{l}\text { Mutual } \\
\text { Funds }\end{array}$} & \multicolumn{6}{|c|}{ Bull market period } & \multicolumn{6}{|c|}{ Bear market period } \\
\hline & Mean & std & Min & Max & Skewness & Kurtosis & Mean & std & Min & $\operatorname{Max}$ & Skewness & Kurtosis \\
\hline 1 & 0.217 & 1.435 & -4.91 & 3.98 & -0.438 & 3.656 & -0.26 & 1.79 & -5.19 & 4.73 & -0.09 & 2.99 \\
\hline 2 & 0.189 & 1.518 & -5.66 & 5.18 & -0.129 & 4.235 & -0.23 & 1.85 & -5.38 & 5.01 & -0.17 & 3.01 \\
\hline 3 & 0.209 & 1.463 & -5.12 & 5.06 & -0.228 & 4.226 & -0.25 & 1.84 & -5.52 & 4.51 & -0.32 & 2.97 \\
\hline 4 & 0.182 & 1.189 & -4.64 & 5.47 & -0.148 & 5.850 & -0.27 & 2.03 & -6.09 & 5.62 & -0.01 & 3.43 \\
\hline 5 & 0.209 & 1.406 & -4.91 & 4.61 & -0.351 & 4.145 & -0.23 & 1.73 & -5.6 & 3.87 & -0.30 & 2.90 \\
\hline 6 & 0.196 & 1.295 & -4.06 & 3.74 & -0.327 & 3.550 & -0.21 & 1.69 & -5.69 & 5.82 & -0.13 & 3.72 \\
\hline 7 & 0.200 & 1.313 & -5.12 & 4.32 & -0.310 & 4.486 & -0.23 & 1.84 & -5.21 & 5.19 & -0.09 & 3.23 \\
\hline 8 & 0.125 & 1.183 & -4.56 & 4.81 & -0.501 & 5.742 & -0.26 & 1.87 & -5.84 & 4.82 & -0.02 & 2.98 \\
\hline 9 & 0.133 & 1.299 & -4.59 & 4.89 & -0.124 & 4.120 & -0.28 & 1.98 & -5.22 & 5.35 & 0.04 & 2.88 \\
\hline 10 & 0.126 & 1.093 & -4.73 & 3.94 & -0.675 & 5.684 & -0.24 & 1.84 & -4.86 & 5.45 & -0.14 & 3.47 \\
\hline 11 & 0.169 & 1.382 & -5.21 & 4.97 & -0.418 & 4.639 & -0.28 & 1.91 & -6.07 & 4.8 & -0.13 & 3.07 \\
\hline 12 & 0.230 & 1.388 & -5.19 & 5.26 & -0.413 & 4.546 & -0.24 & 1.67 & -5.41 & 4.32 & -0.29 & 3.03 \\
\hline 13 & 0.162 & 1.892 & -6.16 & 4.90 & -0.410 & 3.458 & -0.28 & 1.56 & -5.08 & 3.56 & -0.32 & 3.18 \\
\hline 14 & 0.154 & 1.323 & -5.12 & 4.92 & -0.466 & 4.423 & -0.25 & 1.98 & -5.69 & 5.23 & -0.15 & 3.12 \\
\hline 15 & 0.160 & 1.207 & -4.29 & 4.70 & -0.493 & 4.826 & -0.28 & 1.9 & -5.96 & 5.09 & -0.07 & 3.10 \\
\hline 16 & 0.231 & 1.248 & -4.60 & 4.37 & -0.385 & 4.676 & -0.23 & 1.83 & -5.59 & 5.23 & -0.06 & 3.37 \\
\hline 17 & 0.144 & 1.413 & -4.67 & 4.75 & -0.315 & 3.911 & -0.31 & 1.93 & -5.49 & 5.04 & -0.15 & 3.03 \\
\hline 18 & 0.161 & 1.383 & -4.52 & 4.42 & -0.170 & 3.496 & -0.33 & 1.95 & -5.86 & 5.09 & -0.10 & 3.19 \\
\hline 19 & 0.129 & 1.453 & -5.37 & 4.98 & -0.330 & 3.977 & -0.27 & 1.81 & -5.34 & 4.59 & -0.09 & 2.93 \\
\hline 20 & 0.199 & 1.399 & -4.65 & 4.66 & -0.170 & 3.852 & -0.3 & 2.07 & -6.11 & 5.56 & -0.11 & 3.16 \\
\hline 21 & 0.172 & 1.322 & -4.72 & 4.33 & -0.391 & 4.017 & -0.28 & 1.72 & -4.32 & 4.82 & -0.07 & 3.07 \\
\hline 22 & 0.158 & 1.434 & -4.79 & 4.60 & -0.375 & 3.970 & -0.35 & 1.92 & -5.05 & 5.15 & -0.12 & 2.85 \\
\hline 23 & 0.150 & 1.088 & -4.43 & 4.76 & -0.413 & 5.911 & -0.26 & 1.87 & -5.23 & 5.55 & -0.11 & 3.29 \\
\hline 24 & 0.155 & 1.451 & -4.76 & 4.62 & -0.235 & 3.675 & -0.32 & 1.9 & -5.07 & 5.19 & 0.07 & 3.01 \\
\hline 25 & 0.165 & 1.235 & -5.06 & 5.29 & -0.189 & 5.415 & -0.23 & 1.63 & -4.99 & 3.88 & -0.11 & 2.94 \\
\hline 26 & 0.123 & 1.028 & -4.96 & 3.54 & -0.912 & 6.456 & -0.26 & 2.02 & -5.53 & 5.64 & 0.01 & 3.13 \\
\hline 27 & 0.238 & 1.585 & -4.63 & 4.62 & -0.220 & 3.203 & -0.31 & 1.92 & -5.67 & 5.08 & -0.16 & 3.20 \\
\hline 28 & 0.127 & 1.166 & -4.50 & 4.89 & -0.380 & 5.108 & -0.28 & 1.73 & -5.4 & 4.95 & -0.14 & 3.41 \\
\hline 29 & 0.105 & 1.320 & -5.47 & 3.67 & -0.720 & 4.648 & -0.27 & 1.67 & -5.61 & 4.13 & -0.17 & 3.00 \\
\hline 30 & 0.149 & 1.153 & -4.73 & 4.92 & -0.614 & 6.229 & -0.25 & 1.79 & -5.96 & 5.14 & -0.06 & 3.27 \\
\hline
\end{tabular}


Table 2. Classic performance measurement values and ranking of funds

\begin{tabular}{|c|c|c|c|c|c|c|c|c|}
\hline \multirow{2}{*}{$\begin{array}{l}\text { Mutual } \\
\text { Funds }\end{array}$} & \multicolumn{4}{|c|}{ Sharpe ratio } & \multicolumn{4}{|c|}{ Treynor ratio } \\
\hline & Bull & Rank & Bear & Rank & Bull & Rank & Bear & Rank \\
\hline 1 & 0.62 & 8 & -0.57 & 15 & 3.58 & 9 & -5.42 & 12 \\
\hline 2 & 0.46 & 24 & -0.49 & 4 & 3.20 & 13 & -4.65 & 3 \\
\hline 3 & 0.56 & 13 & -0.53 & 9 & 3.70 & 8 & -5.92 & 23 \\
\hline 4 & 0.81 & 1 & -0.56 & 12 & 4.37 & 2 & -5.47 & 14 \\
\hline 5 & 0.66 & 5 & -0.50 & 6 & 4.12 & 3 & -5.55 & 16 \\
\hline 6 & 0.51 & 18 & -0.48 & 3 & 2.80 & 20 & -4.99 & 7 \\
\hline 7 & 0.59 & 12 & -0.47 & 2 & 3.71 & 7 & -4.49 & 1 \\
\hline 8 & 0.60 & 11 & -0.60 & 22 & 2.45 & 24 & -5.49 & 15 \\
\hline 9 & 0.48 & 20 & -0.58 & 19 & 2.57 & 22 & -5.63 & 17 \\
\hline 10 & 0.47 & 21 & -0.51 & 8 & 2.41 & 26 & -4.81 & 5 \\
\hline 11 & 0.47 & 22 & -0.57 & 14 & 2.73 & 21 & -5.39 & 11 \\
\hline 12 & 0.72 & 3 & -0.58 & 18 & 3.86 & 5 & -6.95 & 30 \\
\hline 13 & 0.30 & 29 & -0.70 & 30 & 1.99 & 28 & -6.85 & 29 \\
\hline 14 & 0.51 & 19 & -0.47 & 1 & 3.04 & 14 & -4.66 & 4 \\
\hline 15 & 0.61 & 9 & -0.56 & 11 & 2.84 & 18 & -5.21 & 8 \\
\hline 16 & 0.73 & 2 & -0.49 & 5 & 5.87 & 1 & -4.64 & 2 \\
\hline 17 & 0.34 & 28 & -0.54 & 10 & 2.52 & 23 & -5.32 & 9 \\
\hline 18 & 0.47 & 23 & -0.70 & 29 & 2.82 & 19 & -6.63 & 28 \\
\hline 19 & 0.35 & 27 & -0.63 & 25 & 1.91 & 29 & -6.13 & 24 \\
\hline 20 & 0.63 & 6 & -0.58 & 17 & 3.72 & 6 & -5.68 & 20 \\
\hline 21 & 0.60 & 10 & -0.68 & 28 & 3.25 & 12 & -6.24 & 25 \\
\hline 22 & 0.52 & 17 & -0.64 & 26 & 3.38 & 10 & -6.28 & 26 \\
\hline 23 & 0.54 & 15 & -0.50 & 7 & 2.90 & 17 & -4.97 & 6 \\
\hline 24 & 0.43 & 25 & -0.67 & 27 & 2.96 & 15 & -6.30 & 27 \\
\hline 25 & 0.62 & 7 & -0.57 & 13 & 3.89 & 4 & -5.43 & 13 \\
\hline 26 & 0.54 & 14 & -0.60 & 20 & 2.44 & 25 & -5.64 & 18 \\
\hline 27 & 0.53 & 16 & -0.60 & 21 & 2.91 & 16 & -5.71 & 21 \\
\hline 28 & 0.39 & 26 & -0.60 & 23 & 2.35 & 27 & -5.65 & 19 \\
\hline 29 & 0.26 & 30 & -0.61 & 24 & 1.40 & 30 & -5.81 & 22 \\
\hline 30 & 0.69 & 4 & -0.58 & 16 & 3.26 & 11 & -5.39 & 10 \\
\hline
\end{tabular}

Table 3. The results of three VaR-based RAROC model performance measures

\begin{tabular}{|c|c|c|c|c|c|c|c|c|c|c|c|c|}
\hline \multirow{2}{*}{$\begin{array}{l}\text { Mutual } \\
\text { Funds }\end{array}$} & \multicolumn{4}{|c|}{ SRAROC } & \multicolumn{4}{|c|}{ ERAROC $(\lambda=0.94)$} & \multicolumn{4}{|c|}{$\operatorname{ERAROC}(\lambda=0.97)$} \\
\hline & Bull (\%) & Rank & Bear (\%) & Rank & Bull (\%) & Rank & Bear (\%) & Rank & Bull (\%) & Rank & Bear (\%) & Rank \\
\hline 1 & 1.08 & 6 & -2.19 & 17 & 1.32 & 2 & -1.93 & 20 & 1.10 & 3 & -1.93 & 18 \\
\hline 2 & 0.90 & 18 & -1.80 & 3 & 1.06 & 10 & -1.41 & 4 & 0.87 & 16 & -1.45 & 4 \\
\hline 3 & 1.02 & 11 & -1.98 & 9 & 1.23 & 6 & -2.34 & 27 & 1.02 & 8 & -2.11 & 23 \\
\hline 4 & 1.14 & 3 & -2.06 & 15 & 1.06 & 9 & -1.49 & 8 & 0.99 & 9 & -1.64 & 10 \\
\hline 5 & 1.07 & 7 & -1.88 & 5 & 1.25 & 5 & -2.26 & 26 & 1.05 & 7 & -2.14 & 25 \\
\hline 6 & 1.11 & 4 & -1.67 & 1 & 1.22 & 7 & -1.46 & 6 & 1.08 & 4 & -1.51 & 6 \\
\hline 7 & 1.11 & 5 & -1.81 & 4 & 1.27 & 4 & -1.28 & 3 & 1.07 & 5 & -1.39 & 2 \\
\hline 8 & 0.82 & 23 & -2.04 & 14 & 0.81 & 23 & -1.56 & 11 & 0.72 & 25 & -1.65 & 11 \\
\hline 9 & 0.79 & 26 & -2.19 & 16 & 0.73 & 27 & -1.83 & 17 & 0.68 & 27 & -1.86 & 16 \\
\hline 10 & 0.90 & 19 & -1.92 & 7 & 0.75 & 26 & -1.45 & 5 & 0.72 & 24 & -1.48 & 5 \\
\hline 11 & 0.91 & 17 & -2.23 & 18 & 1.00 & 16 & -1.80 & 16 & 0.84 & 18 & -1.88 & 17 \\
\hline 12 & 1.17 & 2 & -2.01 & 12 & 1.31 & 3 & -2.24 & 25 & 1.11 & 2 & -2.10 & 21 \\
\hline 13 & 0.61 & 30 & -2.71 & 28 & 0.72 & 28 & -2.42 & 28 & 0.60 & 29 & -2.49 & 29 \\
\hline 14 & 0.88 & 20 & -1.89 & 6 & 0.86 & 20 & -1.50 & 9 & 0.80 & 20 & -1.57 & 7 \\
\hline 15 & 1.01 & 13 & -2.27 & 20 & 1.04 & 11 & -1.75 & 15 & 0.93 & 11 & -1.84 & 14 \\
\hline 16 & 1.31 & 1 & -1.77 & 2 & 1.38 & 1 & -1.23 & 1 & 1.25 & 1 & -1.34 & 1 \\
\hline 17 & 0.77 & 27 & -2.54 & 26 & 0.79 & 25 & -2.03 & 24 & 0.70 & 26 & -2.11 & 22 \\
\hline 18 & 0.87 & 21 & -2.73 & 29 & 0.84 & 21 & -1.99 & 21 & 0.78 & 21 & -2.18 & 26 \\
\hline 19 & 0.67 & 28 & -2.24 & 19 & 0.71 & 29 & -1.86 & 19 & 0.61 & 28 & -1.97 & 19 \\
\hline 20 & 1.03 & 10 & -2.31 & 21 & 1.02 & 14 & -1.72 & 12 & 0.93 & 10 & -1.85 & 15 \\
\hline 21 & 0.97 & 15 & -2.39 & 23 & 1.03 & 13 & -1.75 & 14 & 0.90 & 13 & -1.82 & 13 \\
\hline 22 & 0.82 & 24 & -3.27 & 30 & 0.97 & 17 & -2.54 & 29 & 0.82 & 19 & -2.59 & 30 \\
\hline 23 & 1.06 & 8 & -2.03 & 13 & 0.93 & 19 & -1.49 & 7 & 0.88 & 15 & -1.58 & 8 \\
\hline 24 & 0.80 & 25 & -2.70 & 27 & 0.84 & 22 & -2.03 & 22 & 0.75 & 22 & -2.18 & 27 \\
\hline 25 & 1.01 & 12 & -1.99 & 10 & 1.03 & 12 & -1.74 & 13 & 0.91 & 12 & -1.79 & 12 \\
\hline 26 & 0.95 & 16 & -1.95 & 8 & 0.96 & 18 & -1.27 & 2 & 0.86 & 17 & -1.40 & 3 \\
\hline 27 & 1.04 & 9 & -2.52 & 25 & 1.21 & 8 & -1.86 & 18 & 1.06 & 6 & -2.02 & 20 \\
\hline 28 & 0.85 & 22 & -2.45 & 24 & 0.80 & 24 & -2.61 & 30 & 0.74 & 23 & -2.37 & 28 \\
\hline 29 & 0.62 & 29 & -2.33 & 22 & 0.66 & 30 & -2.03 & 23 & 0.57 & 30 & -2.12 & 24 \\
\hline 30 & 0.99 & 14 & -1.99 & 11 & 1.02 & 15 & -1.50 & 10 & 0.90 & 14 & -1.62 & 9 \\
\hline
\end{tabular}


Table 4. The results of GRAROC and HRAROC models performance measures

\begin{tabular}{|c|c|c|c|c|c|c|c|c|}
\hline \multirow{2}{*}{$\begin{array}{l}\text { Mutual } \\
\text { Funds }\end{array}$} & \multicolumn{4}{|c|}{ Sharpe ratio } & \multicolumn{4}{|c|}{ HRAROC } \\
\hline & Bull (\%) & Rank & Bear $(\%)$ & Rank & Bull (\%) & Rank & Bear (\%) & Rank \\
\hline 1 & 1.05 & 9 & -2.06 & 15 & 0.95 & 4 & -2.41 & 12 \\
\hline 2 & 0.94 & 17 & -1.73 & 5 & 0.94 & 7 & -2.29 & 7 \\
\hline 3 & 1.07 & 7 & -1.99 & 12 & 0.94 & 8 & -2.29 & 8 \\
\hline 4 & 1.12 & 5 & -1.74 & 6 & 0.88 & 10 & -2.71 & 20 \\
\hline 5 & 1.09 & 6 & -1.51 & 3 & 0.95 & 5 & -2.06 & 3 \\
\hline 6 & 1.12 & 4 & -1.68 & 4 & 0.97 & 3 & -1.90 & 1 \\
\hline 7 & 1.12 & 3 & -1.26 & 2 & 0.85 & 12 & -1.94 & 2 \\
\hline 8 & 0.76 & 27 & -1.95 & 10 & 0.68 & 25 & -2.66 & 17 \\
\hline 9 & 0.78 & 26 & -2.19 & 19 & 0.65 & 26 & -2.75 & 22 \\
\hline 10 & 0.84 & 22 & -2.08 & 17 & 0.58 & 28 & -2.08 & 4 \\
\hline 11 & 0.95 & 15 & -2.23 & 20 & 0.80 & 15 & -2.70 & 18 \\
\hline 12 & 1.23 & 2 & -1.89 & 8 & 1.03 & 2 & -2.12 & 5 \\
\hline 13 & 0.64 & 30 & -2.94 & 29 & 0.70 & 20 & -2.57 & 15 \\
\hline 14 & 0.88 & 18 & -2.08 & 16 & 0.71 & 18 & -2.30 & 9 \\
\hline 15 & 1.00 & 11 & -1.77 & 7 & 0.76 & 17 & -2.70 & 19 \\
\hline 16 & 1.31 & 1 & -1.24 & 1 & 1.08 & 1 & -2.14 & 6 \\
\hline 17 & 0.78 & 25 & -2.39 & 24 & 0.64 & 27 & -2.89 & 26 \\
\hline 18 & 0.86 & 20 & -2.41 & 25 & 0.71 & 19 & -3.12 & 29 \\
\hline 19 & 0.70 & 28 & -2.25 & 21 & 0.58 & 29 & -2.41 & 11 \\
\hline 20 & 1.04 & 10 & -2.02 & 14 & 0.84 & 13 & -2.77 & 25 \\
\hline 21 & 1.00 & 12 & -2.17 & 18 & 0.85 & 11 & -2.71 & 21 \\
\hline 22 & 0.83 & 23 & -3.17 & 30 & 0.69 & 22 & -3.70 & 30 \\
\hline 23 & 0.94 & 16 & -1.90 & 9 & 0.80 & 14 & -2.63 & 16 \\
\hline 24 & 0.82 & 24 & -2.70 & 28 & 0.70 & 21 & -3.11 & 28 \\
\hline 25 & 0.98 & 14 & -1.99 & 13 & 0.90 & 9 & -2.33 & 10 \\
\hline 26 & 0.86 & 19 & -2.28 & 22 & 0.68 & 24 & -2.76 & 23 \\
\hline 27 & 1.07 & 8 & -2.52 & 27 & 0.95 & 6 & -2.77 & 24 \\
\hline 28 & 0.84 & 21 & -2.45 & 26 & 0.68 & 23 & -2.91 & 27 \\
\hline 29 & 0.64 & 29 & -2.34 & 23 & 0.51 & 30 & -2.45 & 14 \\
\hline 30 & 0.99 & 13 & -1.98 & 11 & 0.78 & 16 & -2.44 & 13 \\
\hline
\end{tabular}

Table 5. Spearman rank correlation on different performance measures

\begin{tabular}{|c|c|c|c|c|c|c|c|}
\hline \multicolumn{8}{|c|}{ Bull market period } \\
\hline Correlation & Sharpe & Treynor & SMRAROC & $\begin{array}{c}\text { EWRAROC } \\
(\lambda=0.94)\end{array}$ & $\begin{array}{c}\text { EWRAROC } \\
(\lambda=0.97)\end{array}$ & GARAROC & HIRAROC \\
\hline Sharpe & 1 & $0.81 * * *$ & $0.81 * * *$ & $0.75^{* * *}$ & $0.78 * * *$ & $0.77 * * *$ & $0.65 * * *$ \\
\hline Treynor & & 1 & $0.75^{* * *}$ & $0.82 * * *$ & $0.80 * * *$ & $0.78^{* * *}$ & $0.72 * * *$ \\
\hline SMRAROC & & & 1 & $0.90 * * *$ & $0.96^{* * *}$ & $0.96^{* * *}$ & $0.86^{* * *}$ \\
\hline $\begin{array}{l}\text { EWRAROC } \\
(\lambda=0.94)\end{array}$ & & & & 1 & $0.98 * * *$ & $0.94 * * *$ & $0.93 * * *$ \\
\hline $\begin{array}{l}\text { EWRAROC } \\
(\lambda=0.97)\end{array}$ & & & & & 1 & $0.97 * * *$ & $0.92 * * *$ \\
\hline \multicolumn{8}{|c|}{ Bear market period } \\
\hline Correlation & Sharpe & Treynor & SMRAROC & $\begin{array}{c}\text { EWRAROC } \\
(\lambda=0.94)\end{array}$ & $\begin{array}{c}\text { EWRAROC } \\
(\lambda=0.97)\end{array}$ & GARAROC & HIRAROC \\
\hline Sharpe & 1 & $0.86^{* * * *}$ & $0.81 * * *$ & $0.55^{* * *}$ & $0.64 * * *$ & $0.75^{* * *}$ & $0.67 * * *$ \\
\hline Treynor & & 1 & $0.68 * * *$ & $0.72 * * *$ & $0.77 * * *$ & $0.62 * * *$ & $0.48 * * *$ \\
\hline SMRAROC & & & 1 & $0.67 * * *$ & $0.77 * * *$ & $0.81 * * *$ & $0.83 * * *$ \\
\hline $\begin{array}{l}\text { EWRAROC } \\
(\lambda=0.94)\end{array}$ & & & & 1 & $0.97 * * *$ & $0.57^{* * *}$ & $0.36^{* *}$ \\
\hline $\begin{array}{l}\text { EWRAROC } \\
(\lambda=0.97)\end{array}$ & & & & & 1 & $0.65^{* * *}$ & $0.49 * * *$ \\
\hline GARAROC & & & & & & 1 & $0.71 * * *$ \\
\hline HIRAROC & & & & & & & 1 \\
\hline
\end{tabular}

Table 6 . Spearman rank correlation test for equity mutual funds persistence

\begin{tabular}{|c|c|c|c|c|c|c|c|}
\hline & Sharpe & Treynor & SRAROC & $\operatorname{ERAROC}(\lambda=0.94)$ & $\operatorname{ERAROC}(\lambda=0.97)$ & GRAROC & HRAROC \\
\hline Correlation & $0.316^{*}$ & 0.155 & $0.563 * * *$ & 0.241 & $0.339^{*}$ & $0.702 * * *$ & $0.450 * *$ \\
\hline P-value & 0.089 & 0.413 & 0.001 & 0.200 & 0.067 & 0.000 & 0.013 \\
\hline
\end{tabular}

